\title{
Environmental interactions to composite elements of all-GFRP Kolding Footbridge
}

\author{
Beata Stankiewicz* \\ Faculty of Civil Engineering and Architecture, Opole University of Technology, Opole, Poland.
}

\begin{abstract}
Structural integrity of a composite material embraces contributions from: materials science and engineering, processing science, design and fabrication technology. It combines a number of interacting factors: the criticality of the application, the accessibility for and ability to inspect vital parts and components, the intended use including load spectrum and time, the consequences of impact, fatigue, temperature and hostile environment, the nature of inherent flaws, the constituent properties of the material system utilized, and it takes into account human factors. Glass fibre-reinforced polymer GFRP pultruded profiles have great potential in the construction industry, presenting certain advantages when compared with traditional materials, including the potentially improved durability under fluctuating levels of environmental factors. The contribution presents analysis of GFRP composite, acquired from cablestayed Fiberline Bridge exploited for 20 years in the fjord area of Kolding, Denmark. The differential scanning calorimetry (DSC) experiments were performed in the GFRP composite bridge material, in order to determine the mass variation and the energy changes suffered by the materials, as a function of temperature and time. Dynamic mechanical analysis (DMA) was allowed to detect thermal effects based on changes in the modulus or damping behavior. Tensile and flexural tests let to observe the decomposition process and had taken information of basic stress parameters of GFRP material used in Kolding Footbridge. Aforementioned analyses of durability are necessary to examine and monitoring for environmentally aged composites bridge elements.
\end{abstract}

\section{Introduction}

Fiber reinforced composite materials are susceptible to low velocity out-of-plane impact events that introduce internal structural damage in the form of inter-ply delamination, transverse matrix cracking, and tensile cracking. This type of damage not only weakens the structure, but is difficult to detect because it occurs at relatively low impact energies and often leaves no visible indication on the material surface. If this damage goes undetected it can slowly grow under alternating or fluctuating stress, leading to a loss in mechanical performance and potential failure [1].

\footnotetext{
${ }^{*}$ Corresponding author: b.stankiewicz@po.opole.pl
} 
Based on the formation mechanism of delamination proposed by Renault, the formation of delamination was illustrated on 45/0/45/45 direction in the comprehensive investigation [2]. There is onset of progressive and intensive microcracks delamination at $45^{\circ}$ to main fibers direction and propagation of cracks is being continued in this order. Once the damage threshold is reached, matrix cracks appear along the fiber direction. Therefore, strips of fibers and resin disjoint in the thickness direction. These disjointed strips will create a zone of tensile stress between two adjacent layers that lead to the formation of delamination. Restricted by the disjointed strips of the adjacent layers, the shape of delamination turns out to be a pair of sector with the damage growing from the impacted side to the bottom side. Microvascular composites have enabled a variety of multifunctional behaviors including self-healing, thermal management, damage sensing, and electromagnetic modulation. However, the presence of vasculature can potentially reduce composite mechanical properties. As recently reviewed by Petya et al., several studies have characterized how microchannels affect properties such as tensile/compressive strength and stiffness, fatigue behavior, mode 1 and mode 2 fracture toughness, low-velocity impact response and interlaminar shear strength [3].

Numerous studies have focused on the environmental degradations of Polymer Matrix Composites in general, and more specifically, aging of Glass Reinforced Polymer (GRP) composites caused by a large variety of aggressive environments. Some of the most recent studies can be found. Very few of them, however, have dealt with the synergistic effects of aging of polymers and GRPs under combinations of several aging conditions. Since this work is concerned with synergistic aging of a group of commercially available GRPs under combined UV radiation, moisture, temperature and time, an emphasis is made here to evaluate the research progress made so far in this very important area of polymer and polymer based composite science [4].

A major difficulty in designing composite structures is how to predict damage initiation and damage evolution, and safe operating limits to ensure structural integrity. It is worth reminding ourselves that our comprehension of structural changes in composite materials, which take place continuously and cumulatively, is simply lacking in detail [5].

Although in structural applications understanding of the changes in the material's strength and stiffness during the exposure to harsh environments is an essential issue, the effects of environmental agents on the mechanical proper rites of pultruded glass fibre reinforced polymer (GFRP) profiles adopted in bridge structures were still not extensively detailed in literature, especially in relation to the long-term durability. However, a number of studies, especially in laboratory conditions, were conducted on the effects of exposure environments on the short-term durability of GFRP composites. Karbhari and Pope [6] and GangaRao et al. [7] investigated the impact of freeze-thaw cycles on composite materials.

Verghese et al. [8] found that the degradation is primarily associated with the microcracking that occurs when the volume of absorbed water changes. Several commercial composites under environmental exposure were studied by Jamond et al. [9] and Malvar et al. [10]. The major outcome of these studies proved that seawater immersion and salt-fog exposure caused the greatest degradation in the mechanical properties. Lopez-Anido et al. [11] investigated the performance of the adhesive bonds of the FRP composite under freeze-thaw cycles.

Synergism in the global aging often occurs when the simultaneous action of several stresses results in an aging effect that differs from that which would be observed if the individual stresses were applied sequentially. For this reason aging models formulated based on laboratory tests have a limited use for practical applications because real life aging conditions are usually far more complex than what can be simulated in a laboratory. When assessing whether the conditions of a polymeric material are critical, it is usually better to 
conduct periodic tests in situ on existing structures (visual inspection, chemical and physical measurements, dynamic tests) than to rely on existing aging models.

Composites made of fibre-reinforced polymers (FRP) are a modern material characterized by low volume weight, relatively high rigidity and strength, high resistance to atmospheric and chemical agents and a great range of geometrical shaping flexibility [1]. These advantages mean that use of polymer composites in various industries is increasing every year. These advantages were also recognized by civil engineers, especially in design of bridges. The material is increasingly being used in selected structural elements, as well as whole objects [12].

GFRP composites are widely used due to their high strength and durability in aggressive environments. The synergy of beneficial features and the parameters of GFRP material undoubtedly lead to a reduction in the life cycle cost (LCC) of bridge structures [13].

This paper has presented the results of experimental research on the physical, chemical, mechanical changes suffered by GFRP pultruded profiles following accelerated exposure to moisture, thermal effects and ultraviolet (UV) radiation from natural, real environment, after 20 years of exploitation. The main focus of the presented research was to demonstrate technical state of GFRP composite material as an integral part of a footbridge structure. The analysis presented in this paper, and based on DSC and DMA tests, pertained to both unspool composite GFRP material (composite 1) and the one after 20 years of natural aging (composite 2).

\section{Tensile and flexural destructive test for GFRP virgin bridge element}

Tensile tests of GFRP element were carried out on $120 \mathrm{~mm}$ long rectangular $(20 \mathrm{~mm} \times 2,5$ $\mathrm{mm}$ ) coupons in accordance with ISO 527-1,4 test standard. Subsequently, specimens were monotonically loaded until failure using Instron Aramis 8801 (Fig. 1) universal testing machine, with a load capacity of $14 \mathrm{kN}$. Tests were carried out under displacement control at an approximate speed of $2.0 \mathrm{~mm} / \mathrm{min}$. The tensile strength for analyzed GFRP element (from Fiberline bridge element) is $300 \mathrm{MPa}$ in final period of test, before full destruction of composite material. Main core of GFRP element has not been destroyed and the tensile strength of this part of material is more than $300 \mathrm{MPa}$, in $0^{\circ}$ direction of glass fibers base. There is formation of microcracks in both back parts of element and at the second phase in main core, during experiments. Then, cracks increase during progressive delamination process to important, finally period of broken glass fibers. The experimental element has been observed in relevant aspect of decomposition using electronic microscopy type KEYENCE VHX-5000 Digital (Fig. 2.). The value of flexural strength obtained in destructive test is $267 \mathrm{MPa}$, using the same Instron Aramis 8801 equipment with video registration. During the whole decomposition process, down tensile fibers have been destroyed, in determination scale. There is onset of progressive and intensive microcracks delamination at $45^{\circ}$ to main fibers direction and propagation of cracks is being continued in this order. The value of flexural strength is very promising in relevant aspect of bridge implementation.

The main damage mechanisms known by experiment involve intra-laminar and interlaminar cracking, and they must explicitly be taken into account. Behaviour of the interface elements may be controlled using a simple cohesive crack model and the maximum load at failure and absorbed energy can be accurately predicted [5]. 


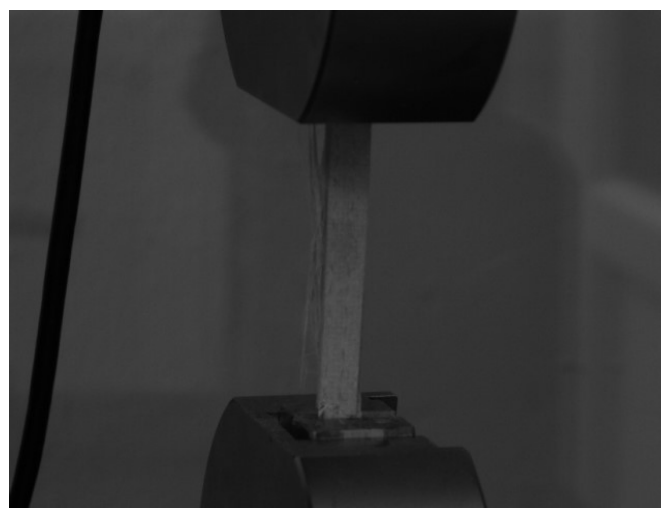

Fig. 1. Tensile test of GFRP element with video registration.

In GFRP laminates, the microcracks that form in the $90^{\circ}$ plies typically span the entire cross-section of the $90^{\circ}$ plies. Thus the potentially three-dimensional problem can be reduced to two dimensions by looking at the edge of the laminate. Due to this simplification, the theory for such microcracking is more advanced then theories for more general forms of microcracking damage. In fact, many results for energy calculations and effective thermoelastic properties can be reduced to a single underlying problem of finding the effect of fully-developed microcracks on the effective axial modulus of the laminate. Although the analysis methods deal only with $90^{\circ}$ ply cracking, the general principles are adaptable to more general microcracking problems in more general laminates. This adaptation, however, requires accounting for microcracks in off-axis plies, for microcracks that do not extend across the full cross section of the cracked plies, for possibly curved microcrack shapes, and for interactions between cracks and delaminations in neighboring plies. In general, accounting for such effects requires the solution of three-dimensional stress analysis problems [14].

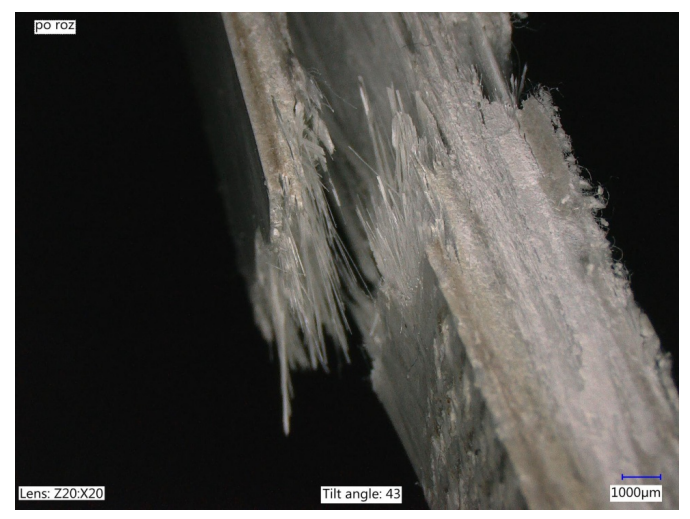

Fig. 2. The broken glass fibers in finally moment of tensile destructive test. 


\section{Thermomechanical analysis of aging composite elements from all-GFRP Kolding Bridge}

\subsection{Comparison DSC analysis for new and old GFRP composite}

The cable-stayed Fiberline Bridge (Fig. 3), located in Kolding city in Denmark, was constructed in 1997 using 12 different pultruded profiles all made of GFRP material. The footbridge is crossing an overhead main railway line near a salt water fjord. The $40.3 \mathrm{~m}$ long and $3.21 \mathrm{~m}$ width footbridge comprises two continuous spans with lengths of 27.9 and $12.4 \mathrm{~m}$, supported by a single A-shaped $18.5 \mathrm{~m}$ tall pylon [15].

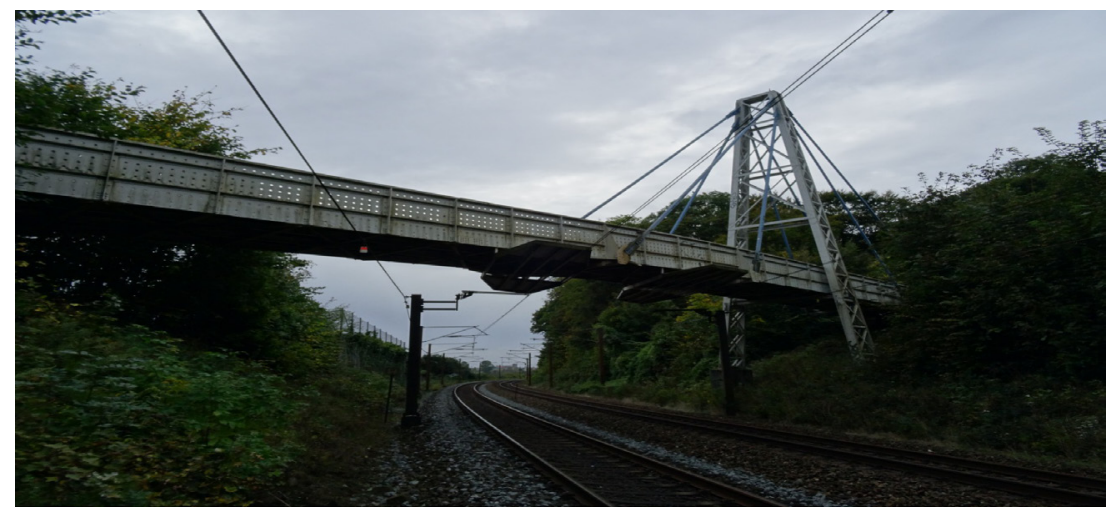

Fig. 3. General view of all-GFRP Kolding Footbridge.

The contribution presents analysis of glass fiber reinforced polymer (GFRP) composite, acquired from cable-stayed Kolding Footbridge exploited for 20 years. Fragment of composite material (composite 2) used in DSC test was therefore subjected to natural aging as a result of temperature amplitudes, permanent solar radiation as well as aggressive impact of sea salt contained in the moisture in the air around coastal area. All results were comprised with DSC analysis effects for new, virgin GFRP Fiberline (composite 1).

Thermal properties of the samples were studied using a Mettler Toledo DSC $822^{\mathrm{e}}$ differential scanning calorimeter. The measurements were performed at the heating rate of $10 \mathrm{~K} / \mathrm{min}$, under nitrogen atmosphere at a flow rate of $60 \mathrm{~mL} / \mathrm{min}$. Samples of about $20 \mathrm{mg}$ were placed in $40 \mu 1$ hermetically sealed aluminum crucibles with a pin.

In the study, specimens of about $20 \mathrm{mg}$ were cut to from reference GFRP (composite 1) and from the composite after 20 years of natural aging (composite 2) and were placed in the hermetically sealed aluminum crucibles with a pin. Samples were heated, during two cycles, from -40 to $250^{\circ} \mathrm{C}$ at a rate of $10 \mathrm{~K} / \mathrm{min}$. In the DSC analysis no phase transition was recorded. The DSC curves from the first and second runs were approximately the same, without exothermic effect, thus no post-curing reaction was observed. The addition of filler in both composites can influence thermal properties of samples and can mask possible phase transitions, especially the glass transition temperature. 


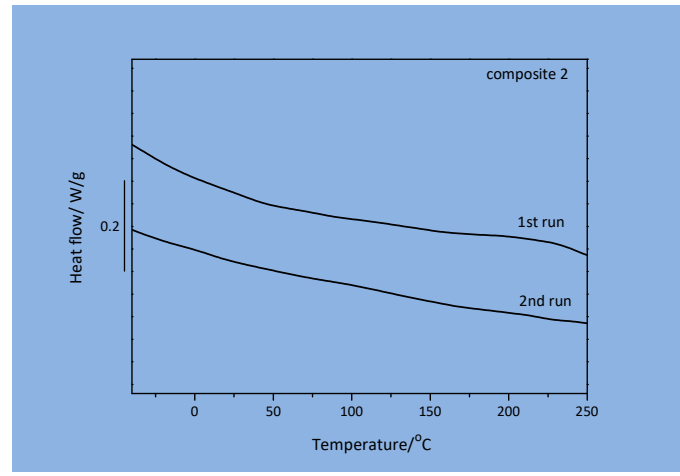

Fig. 4. DSC thermograms of composite 2 (aging one) recorded at heating rate $20 \mathrm{~K} / \mathrm{min}$ in nitrogen.

\subsection{DMA comprehensive analysis}

Dynamic mechanical analysis of both composites (virgin 1 and aging 2) was carried out on a Mettler Toledo DMA/SDTA861 ${ }^{\mathrm{e}}$ apparatus (Fig. 5). An oscillatory dual cantilever bending deformation with displacement amplitude of $10 \mu \mathrm{m}$, force amplitude of $2 \mathrm{~N}$ at a constant frequency of $5 \mathrm{~Hz}$.

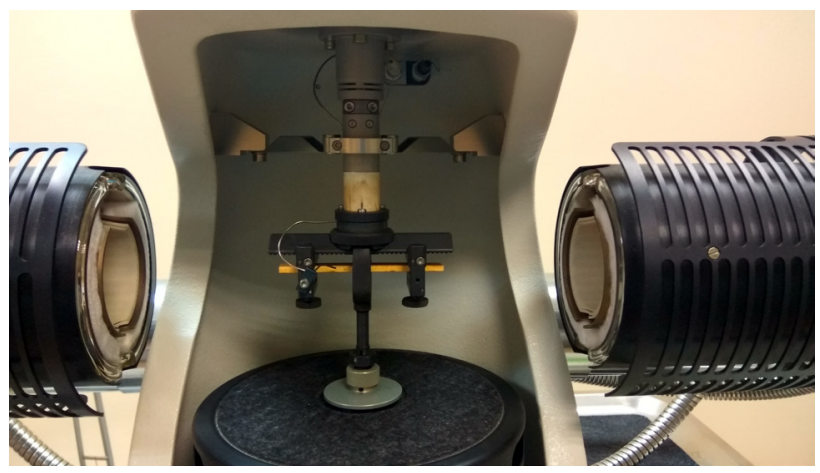

Fig. 5. Mettler Toledo DMA/SDTA861 ${ }^{\mathrm{e}}$ apparatus during test for natural aging composite.

The thermomechanical properties of beams cut from both composites (virgin and aging) were also investigated in the DMA under isothermal conditions, i.e. the samples were deformed at the selected temperatures (at $-30,-5$ and $50^{\circ} \mathrm{C}$ ) for one hour. The changes of the storage modulus as function of time are shown in Figure 6 . The values of the storage modulus at a constant temperature were practically the same at the time of the measurement, but increased with the lowering of a temperature as shown in the Figure 6 . In addition, for the sample from the bridge the modulus at the same temperature was slightly higher than the one for the reference sample. For example at $5^{\circ} \mathrm{C}$ the value of storage modulus is $8443 \mathrm{MPa}$ for the virgin composite 1 and $9254 \mathrm{MPa}$ for the aging composite 2 and at $25{ }^{\circ} \mathrm{C}$, storage modulus for the first GFRP virgin fragment is $8636 \mathrm{MPa}$ and 8981 MPA for the second, old one [16]. 
a)
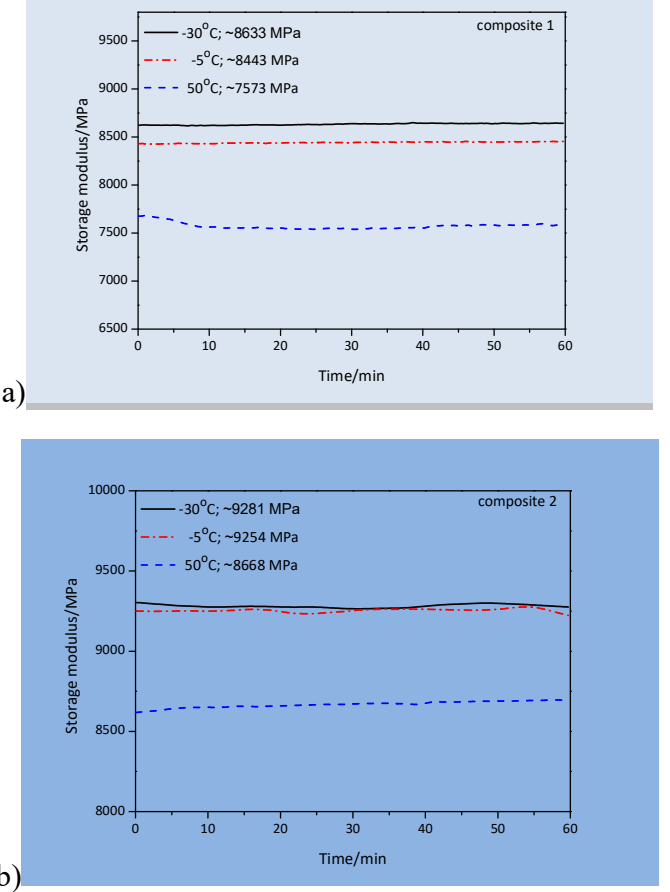

Fig. 6. Time dependence of storage modulus of virgin-new composite 1-(a) and aging-old composite 2-(b).

\section{Conclusions}

The complete results presented in this work, indicate a high potential of GFRP composite for bridge structures. Effects obtained in the tests are used to define the mechanical properties and failure criteria of GFRP pultruded material. The needful destructive tests were conducted for GFRP composite, utilized in bridge structures implementation. The tensile strength for analyzed GFRP virgin Fiberline element was $300 \mathrm{MPa}$ in final period of test, before full destruction of composite material. The value of flexural strength obtained in destructive test was $267 \mathrm{MPa}$.

For the further understanding and application of pultruded GFRP composites under elevated and high temperatures, a series of experiments were conducted to investigate the temperature-dependent thermo-physical and mechanical properties, including the mass-loss, specific heat capacity, thermal conductivity, and storage and loss modulus.

The values of the storage modulus (for virgin and aging composite) at a constant temperature were practically the same at the time of the measurement, but increased with the lowering of a temperature. In addition, for the sample from the bridge the modulus at the same temperature was slightly higher than the one for the reference sample.

For example at $5^{0} \mathrm{C}$ the value of storage modulus was $8443 \mathrm{MPa}$ for the virgin composite 1 and $9254 \mathrm{MPa}$ (10\% more) for the aging composite 2 and at $25{ }^{\circ} \mathrm{C}$, storage modulus for the first GFRP virgin fragment was $8636 \mathrm{MPa}$ and $8981 \mathrm{MPA}$ (about 4\% more) for the second, old one. The level of tensile and flexural strength of aging structure elements was not able to investigate on present stage of research.

The comprehensive research indicated very good technical state of composite material used for all-composite GFRP Kolding Footbridge. The discourse about the results was 
based on a proper research methodology utile for this kind of investigation and monitoring of existing nonconventional bridge structures, without traditional materials.

Kolding Footbridge created by all-GFRP composite panels is extraordinary example of key advantages of the modern structure such as relatively high strength of materials, low self-weight, ease of installation, corrosion resistance, electromagnetic transparency and ease of creation an innovative shapes of pultruded profiles as well as whole structure.

DSC analysis and DMA test validated the expected durability of GFRP pultruded elements of footbridge had exploited for 20 years, in specific environmental conditions among the sea fjord area of Kolding, Denmark.

The outside surface of GFRP composite element taken from the natural environment was porous under the microscope and unregularly covered with moss.

Generally, the arrival of new materials in the field of civil construction such as FRP composites indicates the need for carrying out various estimation tests. It is valuable and important to observe, create monitoring for aging composite, especially after decades of exploitation in real environmental conditions.

All DMA tests, DSC analysis, tensile and flexural tests were carried out at Rzeszow University of Technology in Chemistry Faculty.

\section{References}

1. K. Hart, P. Chia, L. Sheridan, E. Wetzel, N. Sottos, S. White, Compos., Part A 101, 432-443 (2017).

2. H. Wang, S. Longa, X. Zhang, Compos. Struct. 184, 461-473 (2018).

3. S. Petya, J. Aw, A. Gendusa, P. Barnett, Q. Calvert, N. Sottos, S. White, Compos. Struct. 184, 428-436 (2018).

4. L. Tanyi, E. Solis-Ramos, Y. Yun-Bo, M. Kumosa, Polym. Degrad. and Stab. 131, 1-8 (2016).

5. P. Beaumont, C. Soutis, A. Jonhson, Appl. Compos. Mater. (2017) doi:10.1007/s10443-017-9662-0.

6. V. Karbhari, G. Pope, ASCE J. Cold. Reg. Eng. 8(1), 1-20, (1993).

7. H. GangaRao, P. Vijay, P. Dutta, Proceedings of Corrosion, 550, 1-8, (1995).

8. N. Verghese, M. Hayes, K. Garcia, C. Carrier, J. Wood, J. Lesko, Proceedings of the Second International Conference on Fiber Composites in Infrastructure ICCI '98, 2, 720-739, (1998).

9. R. Jamond, T. Hoffard, T. Novinson, L. Malvar, NFESC Special Publication SP-2083SHR, (2000).

10. L. Malvar, R. Jamond, T. Hoffard, T. Novinson, CDCC'02, Montreal, Quebec, Canada, 191-202, (2002).

11. R. Lapoez-Anido, A. Michael, T. Sandford, J. Mater. Civ. Eng. 27, 135-148, (2004).

12. J. Chroscielewski, M. Klasztorny, M. Miskiewicz, M. Romanowski, K. Wilde, 5th Conference Footbridge July 16-18 (2014)

13. T. Siwowski, A. Wiater, Roads and Bridges 16, 285-299 (2017)

14. B. Stankiewicz J. Compos. Mater. 51, 2301-2313 (2017).

15. P. Gorski, B. Stankiewicz, M. Tatara, DYN-WIND Conference May 21-25 (2017).

16. B. Stankiewicz, B. Mossety-Leszczak, L. Byczynski and M. Kisiel, J. Compos. Mater., 1-9 (2017), doi: 10.1177/0021998317749713. 